\title{
Incidence of Phytophthora Root Rot of Fraser Fir in North Carolina and Sensitivity of Isolates of Phytophthora cinnamomi to Metalaxyl
}

\author{
D. M. Benson and L. F. Grand, Department of Plant Pathology, North Carolina State University, Raleigh 27695- \\ 7616
}

\begin{abstract}
Benson, D. M., and Grand, L. F. 2000. Incidence of Phytophthora root rot of Fraser fir in North Carolina and sensitivity of isolates of Phytophthora cinnamomi to metalaxyl. Plant Dis. 84:661664.

A survey of Fraser fir Christmas trees in North Carolina for incidence of Phytophthora root rot was conducted during 1997 and 1998. Field sites (7- to 13-year-old trees) and nursery transplant beds (4- to 5-year-old trees) selected at random were surveyed based on foliar symptoms of Phytophthora root rot. Field sites were surveyed with a random transect method $(>3,000$ trees/field) or by counting all trees $(<3,000$ trees/field). Overall, incidence of Phytophthora root rot averaged $9 \%$ over the 58 field sites sampled, with a range of 0 to $75 \%$. No relationship was found between number of years Fraser fir had been planted in the field site and disease incidence. Disease incidence did not increase as field sites were rotated through second or third crops of Fraser fir. Phytophthora spp. were recovered from 1.8\% of asymptomatic trees sampled from 58 field sites across the state. P. cinnamomi accounted for $91 \%$ of the Phytophthora isolates recovered. In nursery transplant beds where a systematic sampling procedure was used, incidence of diseased trees averaged $2 \%$, with a range of 0 to $12 \%$ across 16 locations. Recovery of Phytophthora spp. averaged 1.2\% from root samples collected from 50 asymptomatic seedlings at each location. Isolates collected from the field and nursery transplant beds were grown on cornmeal agar incorporated with $0,1,1.25,10$, or $100 \mu$ g a.i. metalaxyl $/ \mathrm{ml}$. All 166 isolates of $P$. cinnamomi tested were sensitive to metalaxyl at 1 or $1.25 \mu \mathrm{g}$ a.i. metalaxyl $/ \mathrm{ml}$. Although incidence of Phytophthora root rot has not increased in the state compared to a survey done in 1976 to 1977, the disease continues to limit production of Fraser fir in North Carolina.
\end{abstract}

Fraser fir (Abies fraseri (Pursh.) Poir.), a conifer native to the ridge tops of the Southern Appalachian Mountains in North Carolina, Tennessee, and Virginia, is an important species grown for the Christmas tree market. The production cycle is 13 years or longer; this includes 5 years in nursery seed (3 years) and transplant beds (2 years). Christmas tree production in North Carolina has grown during the last 40 years from a few growers to about 1,600 growers producing trees worth $\$ 78$ million in 1996 (2). The top five counties

Corresponding author: D. M. Benson

E-mail: mike_benson@ncsu.edu

This research was supported by a grant from the North Carolina Christmas Tree Growers Association and by the North Carolina Agricultural Research Service, College of Agriculture and Life Sciences, North Carolina State University, Raleigh.

This publication reports research involving an antimicrobial substance. It does not contain recommendations for its use, nor does it imply that the uses discussed here have been registered. All uses of pesticides must be registered by appropriate state and federal agencies before they can be recommended.

Accepted for publication 29 February 2000.

Publication no. D-2000-0403-01R

(C) 2000 The American Phytopathological Society
(Ashe, Avery, Alleghany, Watauga, and Jackson) accounted for $88 \%$ of North Carolina's tree sales in 1996 (2). Since the first report in 1963 in Penrose, North Carolina (11), Phytophthora root rot, caused primarily by Phytophthora cinnamomi Rands, has become a major limitation to Fraser fir production. In addition to P. cinnamomi, P. citricola Sawada (13) and P. drechsleri Tucker (5) also cause root rot of Fraser fir in North Carolina. Trees planted in poorly drained sites are at considerable risk to Phytophthora root rot $(9,11)$.

In a 1972 survey of Fraser fir in western North Carolina, Grand and Lapp (9) found $10 \%$ incidence of Phytophthora root rot, although individual field sites ranged from $<1$ to $90 \%$ incidence. Fraser fir field sites surveyed in 1976 to 1977 in Avery and Jackson Counties had 1.5 and $12.6 \%$ Phytophthora root rot, respectively (D. M. Benson and R. K. Jones, unpublished data). As Christmas tree production has expanded in North Carolina, there is concern among growers that incidence of Phytophthora root rot has increased as well. Thus, a survey of Fraser fir in western North Carolina production areas was undertaken in 1997 to 1998 to determine whether or not incidence of Phytophthora root rot has increased. Disease incidence was compared for the number of years trees were planted in a field site and the number of Fraser fir crops planted in the same field site. A second objective was to determine if the use of the fungicide metalaxyl on seedlings in nurseries over the past 10 to 15 years has resulted in metalaxyl-insensitive isolates of $P$. cinnamomi. A preliminary report was published (4).

\section{MATERIALS AND METHODS}

Survey area. Five counties in three regions of the state, including Ashe-Alleghany, Avery-Watauga, and Jackson, were selected for the survey. These counties account for $88 \%$ of Fraser fir production in North Carolina. Fraser fir has been grown less than 25 years in Ashe and Alleghany Counties, while production has continued for 40 years or more in the other counties. Field sites in Ashe and Alleghany Counties are generally at lower elevation and have more compacted, less well-drained soils compared to the two other regions. We asked extension agents to select field sites and nursery transplant beds in their county that were representative of Fraser fir production based on tree age and rotation, as well as any perceived problem with Phytophthora root rot. Thus, sites were selected that had no, low, or high incidence of Phytophthora root rot. Nursery transplant beds were included in the survey on the same basis to determine the incidence of Phytophthora root rot and, therefore, the potential for introducing infected transplanting stock to the field.

Field sites. One of two sampling procedures was used for field-planted trees depending on the number of trees per field. For fields with $<3,000$ trees, the entire field was walked and each tree examined for symptoms of Phytophthora root rot. Symptoms include flagging of the lower branches, chlorosis, wilting of new growth, and, most commonly, trees that were totally necrotic or completely defoliated. Root samples were collected from 12 symptomatic trees and, randomly, from 12 asymptomatic trees in each field. For fields with >3,000 trees, a transect method was used wherein three transects of 408 trees (1,224 trees/field) were walked from a randomly chosen, central point and examined for symptoms. Sample size was determined based on an estimated disease incidence of $10 \%$ (9). A root sample was removed from every hundredth tree along the transects for a total of 12 trees. In addition, roots from 12 symptomatic trees 
were collected regardless of location in the field. A total of 58 field plantings were surveyed in the three regions.

Data for disease incidence by years in the field and by the number of Fraser fir crops grown in a particular field was analyzed by PROC GLM with a linear regression model and a logistic regression model from PC SAS (SAS Institute, Inc., Cary, NC). The logistic regression model was tested because of the wide range of disease incidence among the 58 fields.

Root samples were returned to the laboratory in an insulated chest and assayed within $48 \mathrm{~h}$. Roots from an individual tree were washed under running tap water to dislodge soil particles and cut into 5- to 10mm-long segments. Next, 5 to 10 segments each were placed in five clumps on each of two plates per tree containing a penicillinhymexazol. After 24 and $48 \mathrm{~h}$, mycelial growth in the agar was examined microscopically for the presence of Phytophthora spp. hyphae. Axenic cultures were established on cornmeal agar (CMA) for all positive root samples. Isolates were identified to species based on microscopic characteristics. Avery and Jackson Counties were compared to a similar survey done in 1976 to 1977 (D. M. Benson and R. K. Jones, unpublished data). In that survey, all trees in the field site were counted and the number with Phytophthora root rot based on foliar symptoms was used to determine percent Phytophthora root rot for the site. There were 14 field sites in Avery County and six field sites in Jackson County in the 1976 to 1977 survey.

Nursery transplant beds. In production of Fraser fir, seeds are sown in prepared nursery beds with irrigation, and the resulting seedlings allowed to develop for 3 years. After 3 years, seedlings become polymyxin-pimaricin medium (8) with

The results of the field-site survey for

crowded but are too small to be planted directly into the field. Therefore, seedlings are transplanted in rows (generally seven trees wide) to newly prepared nursery transplant beds (about $1 \mathrm{~m}$ wide) for an additional 2 years until the transplants are large enough to plant in the field.

A systematic sampling pattern with 50 transects ( $1 \mathrm{~m}$ wide) was used at each location wherein 1,250 trees were examined for symptoms of Phytophthora root rot and roots from 50 trees were collected and cultured for Phytophthora spp. A total of 16 nursery transplant beds in the three regions were surveyed. At a random starting position, 25 trees nearest a $1-\mathrm{m}$ transect laid $90^{\circ}$ across the bed were examined and roots from one asymptomatic tree were removed. This process was repeated until trees along 50 transects had been examined and sampled. The interval between transects was determined by pacing off the linear distance of the nursery transplant beds to be surveyed at a given location. Roots from any transplants with symptoms of Phytophthora root rot also were collected regardless of position in the transplant bed so that isolates of Phytophthora could be obtained to test for sensitivity to metalaxyl.

Fungicide screening. A total of 166 isolates (115 in 1997 and 51 in 1998) of $P$. cinnamomi collected from the nursery transplant bed and field survey were grown on CMA incorporated with metalaxyl (Subdue 2E) at either 0, 1 (1.25 in 1998 due to calculation error), 10 , or $100 \mu \mathrm{g}$ a.i./ml. Fungal growth was measured after 4 days, when the control culture for each isolate had reached the edge of the plate. Inhibition was determined as the percentage of growth at a given metalaxyl concentration compared to growth in the absence of the fungicide. Isolates with little or no growth at 1 to $1.25 \mu \mathrm{g}$ a.i. metalaxyl/ml were considered sensitive.

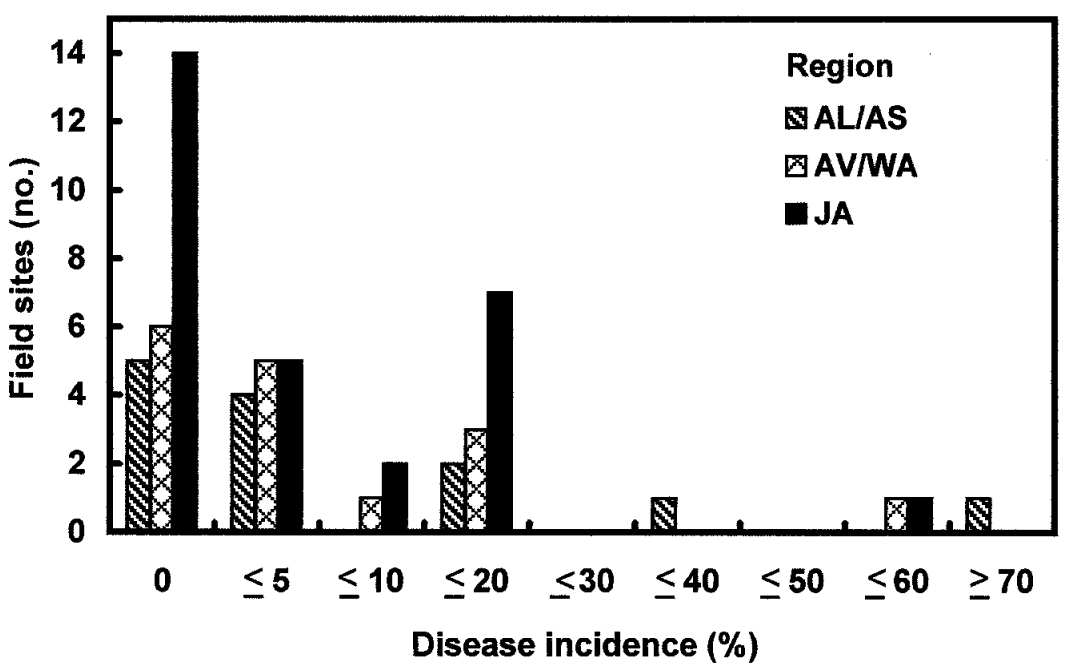

Fig. 1. Number of Fraser fir field sites and incidence of Phytophthora root rot from a survey of 58 field sites in (AL/AS) Alleghany and Ashe Counties, (AV/WA) Avery and Watuaga Counties, and (JA) Jackson County, North Carolina, in 1997 to 1998.

\section{RESULTS AND DISCUSSION}

Disease in field sites. In the 58 field sites, we examined 100,431 Fraser fir trees of various ages and in various rotations for symptoms of Phytophthora root rot. Root samples were collected and cultured from 1,333 trees in the field sites across the three regions. Across field sites, disease incidence was quite variable, ranging from 0 to $75 \%$. Of the field sites surveyed in the three regions, 25 (43\%) had no disease and 14 of the field sites (24\%) had less than 5\% disease incidence (Fig. 1). Only one site in each region $(5 \%)$ had 60 to $75 \%$ disease incidence. Overall, incidence of Phytophthora root rot of Fraser fir in North Carolina averaged $9 \%$ for the 58 field sites sampled. Field sites in the AlleghanyAshe-County region, a relatively new growing region at lower elevation, had the highest disease incidence $(13.1 \%)$ of the three regions, followed by Avery-Watauga with $8.9 \%$ and Jackson with $7.1 \%$ incidence.

Incidence of Phytophthora root rot of Fraser fir found in our survey is comparable to estimates found in earlier surveys. In 1972, Grand and Lapp (9) reported an average disease incidence of $9.6 \%$ for a fivecounty area, with individual field sites ranging from $<1$ to $90 \%$ incidence. First found in Jackson County in 1962 (11), Phytophthora root rot of Fraser fir caused by $P$. cinnamomi was reported on Fraser fir in all production counties within the next 10 years (9). In 1976 and 1977, Benson and Jones (unpublished data) found an incidence of Phytophthora root rot of 4.2 and $7.5 \%$ in a survey of Avery and Jackson Counties, respectively. In the 1976 to 1977 survey, 14 field sites in Avery County had a disease incidence that ranged from near $0 \%$ (10 field sites) to 9 to $14 \%$ (two field sites) to over $17 \%$ (two field sites). In Jackson County, disease incidence ranged from near $2 \%$ (two field sites) to 6 to $9 \%$ (three field sites) to $17.6 \%$ (one field site). Compared to the 1976 to 1977 survey, incidence of Phytophthora root rot has more than tripled in Avery County and remained the same in Jackson County (Table 1).

As the number of years trees were in the field site increased, no significant increase $(P=0.23$, logistic regression model $)$ in incidence of Phytophthora root rot was found. Across the 58 field sites, incidence of Phytophthora root rot averaged 9\% whether the trees had been in the field 1 year or as many as 8 years. This result was unexpected because casual observation of field sites and the known role of water in dispersal of Phytophthora spp. inoculum (9) suggests that disease should increase over time. However, the number of years trees were in the field had no impact on disease incidence; therefore, individual field-site characteristics in relation to drainage patterns and soil physical properties may be more important in develop- 
ment of Phytophthora root rot. Unfortunately, we did not have enough field sites in different aspect or soil-type classes to test this hypothesis.

Field sites surveyed represented locations that had grown one to four crops (rotations) of Fraser fir. Growers normally harvest a crop over a 1- to 3-year period as individual trees in the field reach market size. Transplants are then machine planted in the spring following the cutting of the last trees to be harvested in the field, resulting in a long-term monoculture of Fraser fir. Trees in fields planted to the first and second rotations had 9.5\% $(n=$ $16)$, and $12.3 \%(n=23)$, disease incidence, respectively, with $4.3 \%(n=16)$ incidence in the third rotation and $0 \%(n=2)$ in the fourth rotation. We found no indication $(P$ $=0.54$ ) that Phytophthora root rot was more severe as the number of rotations of Fraser fir increased based on logistic regression $\left(r^{2}=0.24\right)$. Growers tend to avoid replanting fields where severe Phytophthora root rot losses have occurred in the second rotation; thus, it was not unexpected that third and fourth rotations had less root rot than the first and second rotations.

Disease in nursery transplant beds. Incidence of Phytophthora root rot averaged $2.0 \%$ in the 16 nursery transplant beds surveyed across the state. However, disease ranged from 0 to $12 \%$ incidence in individual nursery transplant beds (Fig. 2). Statewide, four nursery transplants beds (25\%) had no disease, $11(69 \%)$ had less than $5 \%$ disease, and one $(6 \%)$ had $11.9 \%$ disease incidence. The mean percent disease incidence in each region was $1.6 \%$ in Alleghany County (no nursery transplant beds surveyed in Ashe County), 0.3\% in Avery-Watauga, and 3\% in Jackson County. The higher incidence in Jackson County resulted from one nursery transplant bed with almost $12 \%$ disease (Fig. 2).

Although the incidence of Phytophthora root rot was low on seedlings in nursery transplant beds, the potential for planting infected stock with the development of disease in field sites is a concern to growers. Doggett et al (7) planted asymptomatic transplants collected from areas of a nursery transplant bed infested with $P$. cinnamomi into a steeply sloping $\left(>30^{\circ}\right)$ field site. Only $36 \%$ of the trees could be harvested 8 years later, compared to $59 \%$ of the trees that were transplanted from noninfested areas of the nursery (7). At the time of lifting trees for field planting, the roots cannot be examined reliably for presence of root rot during the grading process, so only trees with obvious foliar symptoms are discarded. Thus, there is the potential to move infected but asymptomatic trees to the field. We found that $1.2 \%$ of the transplants judged healthy based on visual inspection were actually infected with $P$. cinnamomi (Table 2). Growers normally plant about 4,500 trees/ha; therefore, it is possible that over 50 diseased trees would be planted per hectare. In many field sites, trees growing in areas where surface water channels downslope after heavy rain events develop disease symptoms first. If an infected tree was planted in such an area, Phytophthora spp. inoculum could spread down the drainage path, infecting adjacent trees. This pattern of disease development in a field occurs frequently throughout the region. In addition to movement of inoculum in drainage channels, inoculum could move down slope in planting furrows made by the shank of machine planters when trees are transplanted.

Root isolations. P. cinnamomi was isolated from $1.8 \%$ of the asymptomatic trees and $17.9 \%$ of the symptomatic trees in field sites (Table 2). Isolation frequency was similar for trees in field sites and in nursery transplant beds. The recovery rate of Phytophthora spp. from asymptomatic trees in field sites suggests that over 80 trees/ha look healthy but are actually infected and may develop foliar symptoms of
Phytophthora root rot in the future. The low recovery of Phytophthora spp. from symptomatic trees was probably a result of sampling mostly necrotic trees that had been dead since the previous year. Apparently, $P$. cinnamomi is a poor competitor against invading saprophytes once the tissue had died and, therefore, is difficult to isolate.

$P$. cinnamomi from Fraser fir in field sites and nursery transplant beds accounted for $91 \%$ of the root isolations. P. cactorum (Lebert \& Cohn) J. Schröt. and $P$. dreschleri were recovered from seedlings in nursery transplant beds in addition to an unidentified species (Table 3). Although this is the first report of $P$. cactorum on Fraser fir in North Carolina, several fir species, including Fraser fir, have been reported as hosts for $P$. cactorum in Michigan nurseries (1). Hamm and Hansen (10) recovered $P$. cactorum from several Abies spp. in the Pacific Northwest, but Fraser fir was not included in the sampling. In greenhouse experiments in the Pacific

Table 1. Incidence of Phytophthora root rot of field-planted Fraser fir in Avery and Jackson Counties, North Carolina, in 1976 to 1977 and 1997 to 1998 surveys

\begin{tabular}{lccccc}
\hline & \multicolumn{2}{c}{$\mathbf{1 9 7 6 - 1 9 7 7}^{\mathbf{a}}$} & & \multicolumn{2}{c}{$\mathbf{1 9 9 7 - 1 9 9 8}$} \\
\cline { 2 - 3 } \cline { 5 - 6 } County & Trees surveyed & Root rot $(\%)$ & & Trees surveyed & Root rot $(\boldsymbol{\%})$ \\
\hline Avery & 151,560 & 4.2 & & 12,709 & 13.2 \\
Jackson & 9,198 & 7.5 & & 57,703 & 7.1 \\
\hline
\end{tabular}

${ }^{\text {a }}$ Unpublished data of D. M. Benson and R. K. Jones.

Table 2. Recovery of Phytophthora spp. from asymptomatic and symptomatic Fraser fir in field sites and nursery transplant beds in North Carolina in 1997 to 1998

\begin{tabular}{lccccc}
\hline & \multicolumn{2}{c}{ Field site } & & \multicolumn{2}{c}{ Nursery transplant bed } \\
\cline { 2 - 3 } \cline { 5 - 6 } Category & No. trees sampled & Recovery $(\boldsymbol{\%})$ & & No. trees sampled & Recovery $(\boldsymbol{\%})$ \\
\hline Asymptomatic trees & 734 & 1.8 & & 692 & 1.2 \\
Symptomatic trees & 602 & 17.9 & & 316 & 10.1 \\
\hline
\end{tabular}

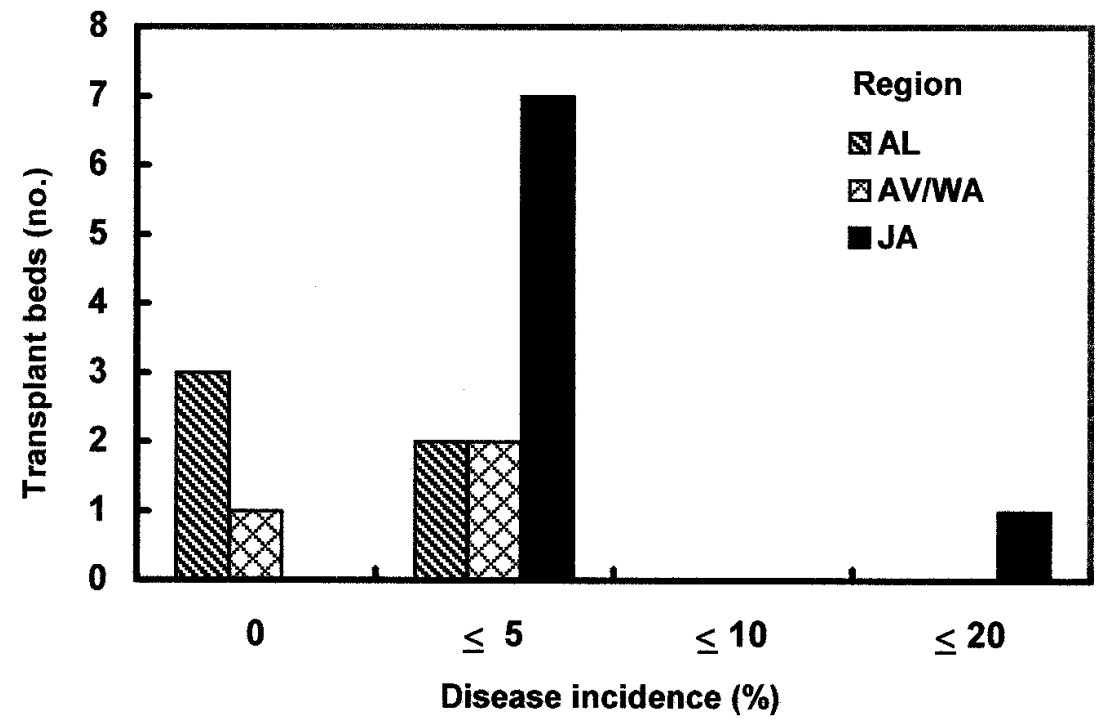

Fig. 2. Number of Fraser fir nursery transplant beds and incidence of Phytophthora root rot from a survey of 16 nursery transplant beds in (AL) Alleghany County, (AV/WA) Avery and Watuaga Counties, and (JA) Jackson County, North Carolina, in 1997 to 1998. 
Table 3. Percentage of Phytophthora spp. recovered from Fraser fir trees in field sites and nursery transplant beds in North Carolina in 1997 to 1998

\begin{tabular}{lcc}
\hline & \multicolumn{2}{c}{ Recovery $(\%)^{\mathbf{a}}$} \\
\cline { 2 - 3 } Species & Fields & Beds \\
\hline P. cinnamomi & 69.3 & 21.9 \\
P. cactorum & 0 & 2.7 \\
P. dreschleri & 0 & 1.1 \\
Phytophthora sp. & 0.5 & 4.4 \\
\hline
\end{tabular}

${ }^{a}$ Based on 182 isolates of Phytophthora spp.

Northwest, $P$. cactorum was less virulent on Fraser fir than $P$. cinnamomi or $P$. cryptogea (6). P. drechsleri has not been reported on Fraser fir outside of North Carolina, but isolates of $P$. drechsleri from Douglas fir (Pseudotsuga menziesii (Mirb.) Franco) in the Pacific Northwest are generally less aggressive to Douglas fir than $P$. cryptogea, a similar fungus (9). The infrequent recovery of other Phytophthora spp. suggests that $P$. cinnamomi is the most common species causing root rot of Fraser fir in North Carolina.

Metalaxyl sensitivity. Compared with the controls, mycelial growth of 80 isolates of $P$. cinnamomi was inhibited an average of $89.3 \%$ at either 1 or $1.25 \mu \mathrm{g}$ a.i. metalaxyl $/ \mathrm{ml}$, while the other 86 isolates were completely inhibited. Previously, Benson (3) found that the $90 \%$ effective dose for inhibition of mycelial growth of $P$. cinnamomi was about $1 \mu \mathrm{g}$ a.i. metalaxyl $/ \mathrm{ml}$. Thus, even though growers may be using metalaxyl two to three times a year for control of Phytophthora root rot in transplant beds, the pathogen has not developed resistance to this fungicide.

In summary, results from this survey indicate that incidence of Phytophthora root rot of Fraser fir has not increased in North Carolina since earlier surveys in the 1970s. Nursery transplants are a potential source of Phytophthora spp. introduction to the field; therefore, disease management practices that suppress Phytophthora spp., such as raised nursery beds, fumigation, and fungicides, should be used in transplant production. All isolates of $P$. cinnamomi recovered from Fraser fir were sensitive to metalaxyl. Although this fungicide remains a useful management tool, growers should use this fungicide only at labeled rates and recommended frequencies to ensure that the fungus remains sensitive to the compound.

\section{ACKNOWLEDGMENTS}

We thank the North Carolina Christmas Tree Growers Association, and the cooperating Christmas tree growers whose field sites and transplant beds were included in the survey, for their support; extension service personnel J. Washington, (AsheAlleghany Counties), J. Moody and D. Hundley (Avery-Watauga Counties), and C. Bredencamp and M. Stroot (Jackson County) for participating in the survey; C. Brownie (North Carolina State University, Department of Statistics) for advice on data analysis; North Carolina State University staff members C. Vernia, W. Gutierrez, B. Daughtry, K. Parker, and D. Watson; and the Plant Pathology graduate students who assisted in various phases of the survey.

\section{LITERATURE CITED}

1. Adams, G. C., Jr., and Bielenin, A. 1988. First report of Phytophthora cactorum and P. citricola causing crown rot of fir species in Michigan. Plant Dis. 72:79
2. Anonymous. 1997. North Carolina Christmas tree survey. Published online by N. C. Agric. Stat. Serv. N. C. Dep. Agric. Consumer Serv. Raleigh, March, 1998.

3. Benson, D. M. 1979. Efficacy and in vitro activity of two systemic acylalanines and ethazole for control of Phytophthora cinnamomi root rot of azalea. Phytopathology 69:174-178.

4. Benson, D. M., and Grand, L. F. 1999. Disease incidence of Phytophthora root rot of Fraser fir in North Carolina. (Abstr.) Phytopathology 89:S6.

5. Benson, D. M., Grand, L. F., and Suggs, E. G. 1976. Root rot of Fraser fir caused by Phytophthora drechsleri. Plant Dis. Rep. 60:238240.

6. Chastagner, G. A., Riley, K. L., and Hamm, P. B. 1990. Susceptibility of Abies spp. to seven Phytophthora spp. (Abstr.) Phytopathology 80:887.

7. Doggett, C. A., Cordell, C. E., and Rogers, D. 1997. Effect of Phytophthora root rot on survival and growth of Fraser fir Christmas trees. Tree Planters' Notes 48:72-75.

8. Eckert, J. W., and Tsao, P. H. 1962. A selective antibiotic medium for isolation of Phy tophthora and Pythium from plant roots. Phytopathology 52:771-777.

9. Grand, L. F., and Lapp, N. A. 1974. Phytophthora cinnamomi root rot of Fraser fir in North Carolina. Plant Dis. Rep. 58:318-320.

10. Hamm, P. B., and Hansen, E. M. 1982. Pathogenicity of Phytophthora species to Pacific Northwest conifers. Eur. J. For. Pathol 12:167-174.

11. Kuhlman, E. G., and Hendrix, F. F., Jr. 1963 Phytophthora root rot of Fraser fir. Plant Dis. Rep. 47:552-553.

12. Reynolds, K. M., Benson, D. M., and Bruck, R. I. 1985. Epidemiology of Phytophthora root rot of Fraser fir: Root colonization and inoculum production. Phytopathology 75:1004-1009.

13. Shew, H. D., and Benson, D. M. 1981. Fraser fir root rot induced by Phytophthora citricola. Plant Dis. 65:688-689. 